\title{
DIAGNÓSTICO SOROLÓGICO DA ESTRONGILOIDÍASE HUMANA ATRAVÉS DO MÉTODO IMUNOENZIMÁTICO
}

\author{
Regina Brasil, Roberto Badaró, Jacy A. F. de Andrade, \\ Tarcislo M. de Andrade e Edgar M. Carvalho
}

\begin{abstract}
O presente trabalho demonstra a eficácia do método imunoenzimático utilizando antígeno solúvel de larvas de Strongyloides stercoralis no diagnóstico da estrongiloidiase humana. Foram avaliados 27 pacientes com as diversas formas clínicas da parasitose, sendo demonstrados títulos significativos em 25 (92\%) dos casos. Em 17 controles, com ou sem outras parasitoses intestinais, titulos significativos estavam presentes em 3 (18\%). A sensibilidade do teste foi de $92 \%$ e a especificidade de $82 \%$.

São também relatados 3 casos clínicos, nos quais o diagnóstico da doença foi feito inicialmente pela determinação de anticorpos contra larvas de $\mathbf{S}$. stercoralis, havendo posteriormente demonstração parasitológica em 2 dos casos. É ressaltada a importância do teste no diagnóstico da estrongiloidiase aguda e em situaçōes onde eosinofilia não esteja associada a outras condições clínicas.
\end{abstract}

Palavras-chaves: Strongyloides stercoralis. Estrongiloidíase. Método ELISA.

\section{INTRODUÇÃO}

A estrogiloidiase é uma helmintíase endêmica em vários locais do mundo, sobretudo em regiões tropicais 68262729 . A despeito do método de detecção do parasita nas fezes ser fácil, tem sido amplamente documentado que em situações especiais o diagnóstico dessa parasitosł mesmo em formas graves, só tem sido realizado post-mortem 479121415192528 .

Tentativas tẹm sido feitas no sentido de melhorar os métodos diagnósticos dessa parasitose através da utilização de exames imunológicos.

Diversos estudos têm demonstrado o valor da sorologia na detecção de anticorpos antilarvas do $S$. stercoralis através de diferentes técnicas, e mais recentemente pelo método imunoenzimático ELI$S^{2} 35111617233033$. Entretanto, nos métodos indiretos para detectar infecção, até que antígenos específicos tenham sido isolados, a reatividade cruzada ainda representa uma dificuldade para o diagnóstico 10212224 . Esse problema pode ser mais relevante em nosso meio, devido à alta prevalência de outras parasitores intestinais associadas 18131820 .

No presente trabalho, determinamos o valor da sorologia no diagnóstico da estrongiloidíase, desta-

Endereço para correspondência: Dra. Regina Brasil-Hospital Professor Edgard Santos, Laboratório de Imunologia Rua João das Botas, s/n, Canela - 40140 Salvador, Bahia, Brasil.

Laboratório de Imunologia do Hospital Professor Edgard Santos, Faculdade de Medicina da Univesidade Federal da Bahia.

Recebido para publicação em 12/1/87. cando sua importância em situaçōes onde houve grande dificuldade de detecção do parasita nas fezes.

\section{MATERIAL E MÉTODOS}

\section{Grupo analisado}

Foram analisados soros de um total de 27 pacientes, com diagnóstico comprovado de estrongiloidiase, através da identificação de larvas de $S$. stercoralis no material fecal, os quais foram acompanhados no Hospital Professor Edgard Santos, Hospital Couto Maia e Hospital Santo Antônio (Salvador, Bahia). Desses 27 pacientes, 19 eram do sexo masculino e 8 do sexo feminino com idade variando de 2-64 anos, com mediana de 40 anos. $O$ grupo-controle foi constituído por 17 pacientes, sendo 11 portadores de outras parasitoses intestinais e 6 individuos sadios que, em 3 exames parasitológicos de fezes realizados pelo método de Baerman, não foram detectadas larvas de $\boldsymbol{S}$. stercoralis. Todos os individuos do grupocontrole negavam história de estrongiloidiase no passado. Entre os 17 pacientes, 5 eram do sexo masculino e 12 do sexo feminino, com idade variando de 22-54 anos, e mediana de 38 anos. No presente trabalho são também relatados 3 casos nos quais o diagnóstico de estrongiloidíase foi realizado a despeito da não documentação do parasita em vários exames parasitológicos de fezes pelo método de Baerman.

\section{Teste sorológico}

\section{Preparação do antígeno}

Fezes de pacientes portadores de estrongiloidíase foram cultivadas em carvão ativado úmido para 
obtenção de larvas filariformes de $S$. stercoralis, segundo metodologia descrita anteriormente ${ }^{30}$. Após 7 dias as larvas de $S$. stercoralis foram colhidas da cultura através do método de Baerman e concentradas por centrifugação $\left(600 \mathrm{~g} 15 \mathrm{~min}\right.$ a $\left.4^{\circ} \mathrm{C}\right)$. Em seguida as larvas foram lavadas 6 vezes com tampão fosfato $\mathrm{pH}$ 7,2 em centrifugação a $150 \mathrm{~g}$ por 3 minutos. As larvas limpas foram rompidas para extração protéica através de sonificação em 4 periodos de 20 segundos com intervalo de 4 minutos em banhode gelo. $O$ material foi centrifugado a $16000 \mathrm{~g}$ por 30 minutos a $4{ }^{\circ} \mathrm{C}$. O sobrenadante foi colhido, determinado o conteúdo protéico através do método de Lowry, e estocado a $-70^{\circ} \mathrm{C}$ até o uso. (Este antígeno foi gentilmente cedido pelo Dr. Robert M. Genta).

\section{Teste imunoenzimático}

Placas de microtitulação (Linbro EIA Flow Laboratories Inc.) plásticas, fundo chato, foram sensibilizadas com $100 \mu 1$ de uma solução antigênica de $S$. stercoralis na concentração de $10 \mu \mathrm{g} / \mathrm{ml}$ em tampão carbonato-bicarbonato $\mathrm{pH} 9,6$ durante 18 horas a $4^{\circ} \mathrm{C}$. Após 3 lavagens sucessivas de 5 minutos com solução de Tween 20 a $0.05 \%$ em tampão fosfato (PBST), as placas sensibilizadas foram secadas e guardadas envoltas em papel alumínio em freezer a $-20^{\circ} \mathrm{C}$ até o uso.

Diluições seriadas de cada soro a partir de $1 / 4$ até $1 / 4096$ foram preparadas em PBST e $100 \mu l$ de cada diluição foi incubada nas placas sensibilizadas por 45 minutos a $37^{\circ} \mathrm{C}$. Em seguida as placas foram novamente lavadas 3 vezes com PBST e adicionado $100 \mu 1$ do conjugado (IgG de cabra anti-IgG humano ligado à fosfatase alcalina Sigma A-3150, St. Louis MO. USA) previamente diluído a $1 / 1000$ em PBST. Do mesmo modo anteriormente descrito, as placas foram incubadas e lavadas, após o que o substrato enzimático p-nitrofenilfosfato (Sigma 104-105. St. Louis, MO. USA) foi diluido, em tampão carbonatobicarbonato, $1 \mathrm{mM}$ de $\mathrm{MgCl}_{2}$ e $100 \mu \mathrm{l}$ dessa solução foram incubadas na placa à temperatura ambiente para obtenção da reação. Decorridos 30 minutos o desenvolvimento da reação foi interrompido através da adição em cada orifício da placa de $50 \mu$ de hidróxido de sódio 3N. Leitura espectofotométrica em Multiskan foi realizada em Filtro $405 \mathrm{Nn}$. As absorvâncias apresentadas por cada orifício foram comparadas com aquelas obtidas de controles positivos e negativos. Absorvâncias $\geq$ à média \pm 2 desvios-padrōes dos controles negativos foram considerados positivos.

\section{RESULTADOS}

I. Deteção de IgG antilarvas de $\mathbf{S}$. stercoralis em soros de pacientes com estrongiloidiase e em controles

A Figura 1 apresenta a distribuição dos títulos

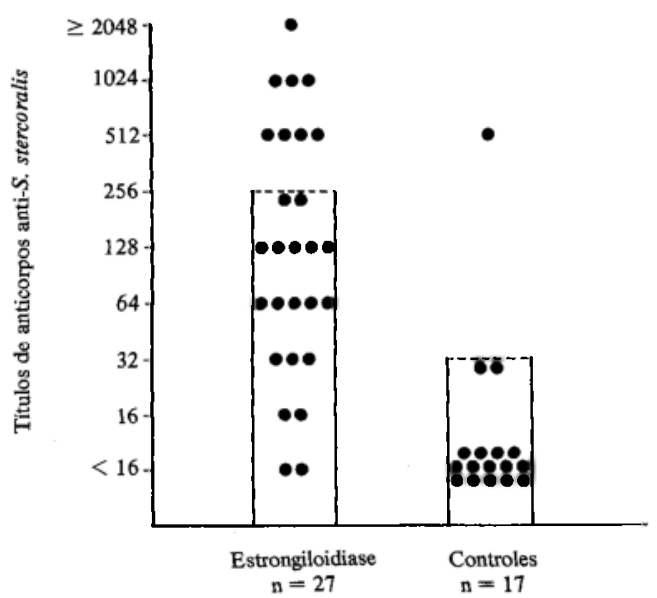

FIG. 1 - OISTRIBUIÇÃO DOS TÍTULOS DE ANTICORPOS ANTI-LARVAS OE S. stercoralis EM PACIENTES COM ESTRONGILOIDIASE E EM CONTROLES.

Fig. 1-Distribuiçáo dos titulos de anticorpos antilarvas de $\mathbf{S}$. stercoralis em pacientes com estrongiloidiase e em controles.

de anticorpos em 27 pacientes com estrongiloidíase, e em 17 controles. Os pacientes apresentaram desde ausência de anticorpos até títulos de 2048, com média de $324 \pm 471$ e mediana de 256 . Entre os pacientes com estrongiloidiase, 6 apresentavam a forma grave da doença, 11 eram sintomáticos e 10 assintomáticos, conforme os critérios adotados em publicação prévia $^{10}$. Entre os pacientes com a forma grave da doença, os titulos de anticorpos variaram de negativos a $\geq$ 1024, com média de $448 \pm 124$ e mediana de 256 . Nos pacientes com a forma sintomática, a variação dos títulos de anticorpos foi de 16 a $>1024$, com média de $304 \pm 382$ e mediana de 128 . Os pacientes assintomáticos mostravam variação dos títulos de anticorpos de negativo a $>2048$, com média de 276 \pm 628 e mediana de 48 . Entre os controles houve variação dos títulos de anticorpos de negativo a 512 , com média de $34 \pm 124$ e mediana negativa. Quando comparada as médias dos controles com os pacientes com estrongiloidiase, houve uma diferença estatisticamente significante com $p<0,005$, entretanto esta diferença não pôde ser demonstrada entre os grupos com estrongiloidiase.

Considerando-se positivos os títulos de anticorpos de 16 , foi documentada a sensibilidade do teste de $91,66 \%$ e a especificidade de $82,35 \%$.

Conforme demonstrado na Figura 1, no total de 27 casos, dois pacientes apresentavam título $\leq 16$, sendo que, nestes, um era assintomático para a estrongiloidiase, e portador de insuficiência renal crônica, e o outro apresentava a forma grave da parasitose, sendo portador de eczema e conjuntivite crônica. Entre os 17 
Brasil R, Badaró R, Andrade JAF, Andrade TM, Carvalho EM. Diagnóstico sorológico da estrongiloidiase humana atra vés do método imunoenzimático. Revista da Sociedade Brasileira de Medicina Tropical 21: 139-143, Jul-Set, 1988

controles, 11 apresentavam outro tipo de parasitose e/ou outra doença associada (giardíase, tricocefalíase, amebiase, ancilostomiase, ascaridiase, hipertensão portal esquistossomótica, miocardite crônica chagásica, tuberculose). Entre eles. 3 pacientes apresentavam títulos significativos de anticorpos, sendo que 1 tinha amebiase, e o titulo foi de 32; outro apresentava ancilostomídeos, $A$. lumbricoides e $T$. trichiuris e o Título foi de 32, e o terceiro era portador de ancilostomideos, S. mansoni, A. lumbricoides e $T$. trichiuris e o titulo foi de 512 .

\section{Relato de casos documentando a importância da sorologia no diagnóstico de estrongiloidíase}

Entre os pacientes com estrongiloidiase, destacamos 3 casos onde o teste imunoenzimático foi o método através do qual se conseguiu elucidação da suspeita diagnóstica.

\section{1. caso:}

J.S.A.N., masculino, branco, com 2 anos, residente em Salvador (BA), foi internado em janeiro de 1984 com quadro de vômitos incoerciveis, dor abdominal, diarréia e desidratação. Evoluiu em 4 semanas sem febre, com piora da epigastralgia e acentuação da diarréia, com fezes fétidas, e franca anasarca. Havia proeminente distensão abdominal, com sinais de ascite e edema de MMII além de derrame pleural e hepatosplenomegalia. $\mathrm{Na}$ avaliação laboratorial, o leucograma agresentava contagem global normal com aneosinofilia. Nos exames bioquímicos, transaminases, uréia, creatinina, colesterol e amilase estavam normais. As proteinas totais e frações, inicialmente normais, apresentam, no decurso de evolução, acentuada hipoalbuminemia $(1,5 \mathrm{~g} \%)$, e hipogamaglobulinemia $(1,2 \mathrm{~g} \%)$. Durante a investigação foram realizados 11 exames parasitológicos de fezes, incluindo Baerman, todos negativos. Entretanto, um forte antecedente epidemiológico, sugestivo de estrongiloidiase (o paciente e o irmão apresentaram larvas migrans cutâneas após exposição à areia, semanas antes do quadro referido), associado ao evidente quadro clínico, motivaram a realização do teste sorológico para anticorpos antilarvas de $S$. stercoralis, cujo resultado revelou um título de 512 . Iniciada a terapêutica com thiabendazol, houve rápida melhora da dor epigástrica, recuperação do apetite e desaparecimento progressivo da ascite e distenção abdominal. Após 6 meses do tratamento, o menor estava bem e a sorologia para anticorpos antilarvas de $S$. stercoralis foi negativa.

\section{$20^{\circ}$ caso}

R.M.B.S., feminina, parda, com 27 anos, médica, residente em Salvador (BA), foi atendida em abril de 1984, com história de febre e dor acentuada em região cervical há 18 dias. $\mathrm{Na} 3$ a semana de doença, apresentou também diarréia durante 3 dias, além de tosse seca, persistente, artralgias em punhos e joelhos, e exantema urticariforme em placas, na região torácica e abdominal que perduraram por \pm 3 dias. Ao exame fisico apresentava temperatura $37,8^{\circ} \mathrm{C}$ sem alteraçōes em exame segmentar. O leucograma revelou 21.000 leucócitos $/ \mathrm{mm}^{3}$ com $45 \%$ de eosinófilos. $\mathrm{O}$ parasitológico de fezes foi negativo e o $\mathbf{R x}$ de tórax normal. $\mathrm{O}$ título sorológico de anticorpos antilarvas de $S$. stercoralis foi 512 . Um novo exame de fezes com Baerman, após 1 semana, evidenciou a presença de $S$. stercoralis, além de $A$. lumbricoides, $E$. nana e $T$. trichiuris. Foi tratada com thiabendazol, regredindo toda sintomatologia em poucos dias. $\mathrm{O}$ exame coprológico e o teste sorológico de controle, realizados 3 meses após, foram negativos. Essa paciente havia realizado, 1 ano antes desse episódio, 3 exames parasitológicos de fezes com Baerman e sorologia para anticorpos antilarvas de $S$. stercoralis pelo método imunoenzimático, sendo todos os exames negativos, pois a mesma representou um dos controles de um inquérito sorológico para estrongiloidíase.

\section{3. caso}

E.B., masculino, pardo, com 45 anos, médico, residente em Salvador (BA). Em uma avaliação laboratorial de rotina, em março de 1985 , foi evidenciado um leucograma de 8.300 leucócitos $/ \mathrm{mm}^{3}$, com presença de $18 \%$ de eosinófilos. Realizou então exames parasitológicos de fezes com Baerman, ambos negativos. Em outubro de 1985, após episódio fugaz de erupção cutânea, realizou novo leucograma com 6.300 leucócitos $/ \mathrm{mm}^{3}$, mantendo $18 \%$ de eosinófilos. Outro parasitológico de fezes com Baerman continuou com resultado negativo. Ainda sem sintomas, realizou mais 2 leucogramas: em fevereiro de 1986 com 10.600 leucócitos $/ \mathrm{mm}^{3}$ e $14 \%$ de eosinófilos e em março de $1986 \mathrm{com} 4.900$ leucócitos $/ \mathrm{mm}^{3}$ e $9 \%$ de eosinófilos. Novo Baerman persistia negativo. Realizou então sorologia para anticorpos antilarvas de $S$. stercoralis, pelo método imunoenzimático, sendo detectado título de 2048. Realizou novos exames de fezes posteriormente, tendo sido demonstrada a presença de larvas de $S$. stercoralis. Fez uso de thiabendazol, e em maio de 1986 o leucograma revelou 7.000 leucócitos $/ \mathrm{mm}^{3}$ com $5 \%$ de eosinófilos. O exame de Baerman realizado após o tratamento foi negativo.

\section{DISCUSSÃO}

O presente estudo demonstra que o teste sorológico pela técnica imunoenzimática para o diagnóstico de estrongiloidiase tem alta sensibilidade (92\%) e especificidade ( $82 \%$ ) e pode representar, em circunstâncias especiais, o método-chave para elucidação do quadro clínico desta parasitose. Os resultados que 
Brasil R, Badaró R, Andrade JAF, Andrade TM, Carvalho EM. Diagnóstico sorológico da estrongiloidíase humana através do método imunoenzimático. Revista da Sociedade Brasileira de Medicina Tropical 21: 139-143, Jul-Set, 1988

obtivemos são compatíveis com os demonstrados por outros autores em áreas diversas, onde foram relatadas sensibilidade e especificidade em torno de $80 \% 22313234$. Isso reforça a possibilidade da utilização dessa técnica mesmo em áreas de alta prevalência de parasitoses intestinais, como a nossa.

No presente estudo, o teste imunológico não detectou anticorpos em 2 pacientes com diagnóstico comprovado de estrongiloidíase. Um desses pacientes, por 3 vezes, teve a forma grave da parasitose após terapêutica específica, mesmo sem história que pudesse sugerir recontaminação. Apresentava eczema e conjuntivite crônica, mas os testes imunológicos realizados não demonstraram defeitos da resposta imune celular ou humoral. É provável, portanto, que este paciente apresentasse uma deficiência imunológica específica contra antígenos do parasita, o que explicaria a suscetibilidade de desenvolver formas graves da estrongiloidíase e a ausência de anticorpos contra o mesmo. $O$ outro paciente com teste negativo apresentava a forma assintomática da doença, forma clínica na qual foram detectados os titulos mais baixos de anticorpos contra o $S$. stercoralis.

O teste sorológico imunoenzimático foi positivo em 3 controles onde não se documentou a presença de larvas de $S$. stercoralis pelo exame parasitológico de fezes. Isso poderia ser conseqüência de associação múltipla de parasitos, resultando em reação cruzada, pois em nossos controles o título mais elevado de anticorpo foi encontrado em 1 paciente que era portador de infestação parasitária múltipla. Entretanto, não pode ser afastada a possibilidade da existência de infecção pelo $S$. stercoralis nesses pacientes, apesar do exame coprológico negativo.

Neste estudo são também ralatados 3 casos de pacientes, com infecção pelo $S$. stercoralis, nos quais o teste sorológico foi positivo a despeito da negatividade dos exames coprológicos iniciais, possibilitando diagnóstico e tratamento necessários. Em um destes pacientes, não se conseguiu demonstrar a presença de larvas de $S$. stercoralis, entretanto, o quadro clinico sugestivo e grave, associado à completa recuperação após a instituição do tratamento específico, respalda a confiabilidade do teste sorológico. Nos outros 2 casos, apesar da não identificação do parasita nos exames iniciais, essa comprovaçāo foi obtida posteriormente devido à insistente procura, motivada pelo resultado do teste sorológico.

Em resumo, o presente trabalho destaca o valor do teste sorológico pela técnica imunoenzimática, no diagnóstico da estrongiloidíase, principalmente nas formas agudas da doença ou em situações onde, a despeito da ausência de sintomatologia, eosinofilia seja documentada no sangue periférico. Embora ainda sejam necessários estudos com maior número de individuos, principalmente do grupo-controle, os resultados iniciais aqui relatados mostram que o teste tem uma boa sensibilidade e especificidade e se constituirá um método diagnóstico adicional importante para estrongiloidiase, especialmente na fase aguda da doença e em pacientes que apresentam eosinofilia não explicada.

\section{SUMMARY}

The detection of antibodies to $\mathbf{S}$. stercoralis antigen by using the Enzyme Linked Immunosorbent Assay was evaluated in 27 patients with strongyloidiasis diagnosed by demonstration of larvae of $\mathrm{S}$. stercoralis in the stool. Significant titers of antibody were observed in 25 (92\%) patients. In 17 controls with or without other parasitic infections, titers were considered positive in 3 (18\%). We also report three cases in which the diagnosis of strongyloidiais was initially made only by the serological test. These observations suggest that documentation of antibody to $\mathrm{S}$. stercoralis by the ELISA technique may contribute to the diagnosis of strongyloidiasis. In addition, the test may be ofgreat value in acute strongyloidiasis and in the diagnosis of patients with unexplained eosinophilia.

Key-words: Strongyloidiasis. ELISA technique. Strongyloides stercoralis. Severe strongyloidiasis.

\section{AGRADECIMENTOS}

Somos gratos a Sra. Maria de La Glória Orge Orge pela colaboração nos exames sorológicos, a Sra. Aracy Ferreira Silva pelo auxílio na realização dos exames parasitológicos.

\section{REFERÊNCIAS BIBLIOGRÁFICAS}

1. Asami K, Enomoto Y, Miura S. Infestações por ancilostomideos e Strongyloides stercoralis em Pernambuco. Inquérito baseado na identificação das larvas. Revista do Instituto de Medicina Tropical de São Paulo 12:31-35, 1970.

2. Badaró R, Carvalho EM, Santos RMB, Gam A, Genta RM. Parasite-specific humoral response in different clinical forms of strongyloidiasis. Transactions of the Royal Society of Tropical Medicine and Hygiene, In press.

3. Bezjak B. Immunoglobulin studies in strongyloidiasis with special reference to raised serum IgE levels. The American Journal of Tropical Medicine and Hygiene 24:945-948, 1975.

4. Bradley SL, Dines DE, Brewer NS. Disseminated Strongyloides stercoralis in an immunosuppressed host. Mayo Clinic Proceedings 53:332-335, 1978.

5. Brannon MJC, Faust EC. Preparation and testing of a specific antigen for diagnosis of human strongyloidiasis. The American Journal of Tropical Medicine 29:229 239, 1949. 
6. Bras G, Richards RC, Irvine RA, Milner PFA, Ragbeer NBS. Infection with Strongyloides stercoralis in Jamaica. The Lancet 2:1257-1260, 1964.

7. Brown HW, Perna VP. An overwhelming strongyloides infection. Journal of the American Medical Association 168:1648-1651, 1958.

8. Campos R, Gazoni E, Silva JH. Incidencia do Strongyloides stercoralis em lavradores do litoral do Estado de São Paulo. Revista Paulista de Medicina 58:17-18, 1961.

9. Carvalho EM. Bacteremia em portadores de estrongiloidiase grave. Importância do verme como veículo e agente propiciador de infecção bacteriana. Tese de Mestrado, Universidade Federal da Bahia, 1977.

10. Carvalho EM. Strongyloidiasis. Clinics in Gastroenterology 7:179-200, 1978.

11. Carvalho EM, Andrade TM, Andrade JA, Rocha $H$. Immunological features in different clinical forms of Strongyloidiasis. Transactions of the Royal Society of Tropical Medicine and Hygiene 77:346-349, 1983.

12. Civantos F, Robinson MJ. Fatal strongyloidiasis following corticosteroid therapy. American Journal of Digestive Diseases 14: 643-651, 1969.

13. Coutinho JO, Campos E, Amato Neto V. Incidência do Strongyloides stercoralis em crianças de São Paulo. Inquérito coprológico efetuado pelos processos de Faust e Cols., de Hoffman, Pons e Janer e de Maermann. Revista do Hospital das Clínicas 7:302-307, 1952.

14. Cruz T, Rebouças $G$, Rocha $H$. Fatal strongyloidiasis in patients receiving corticosteroide. New England Journal of Medicine 275:1093-1096, 1966.

15. Cuni LJ, Rosner F, Charwla SK. Fatal strongyloidiasis in immunosuppressed patients. New York State Journal of Medicine 77: 109-2113, 1977.

16. Dafalla AA. The indirect fluorescent antibody test for the serodiagnosis of strongyloidiasis. Journal of Tropical Medicine and Hygiene 75:109-11, 1972.

17. Dawkins HJ, Grove DI. Transfer by serum and cells of resistance to infection with Strongyloides ratti in mice. Immunology 43:322, 1981 .

18. Dias JCS. Observações sobre a estrongiloidose no Oeste de Minas Gerais, Brasil. Revista do Instituto de Medicina Tropical de São Paulo 10:305-311, 1968.

19. Dwork KG, Jaffe JR, Lieberman HD. Strongyloidiasis with massive hyperinfection. New York State Journal of Medicine. 75: 1230-1234, 1975.

20. Farias JAS. Prevalência de helmintos em escolares de 7 a 14 anos na Cidade do Salvador. Revista da Sociedade Brasileira de Medicina Tropical 6:261-269, 1972.

21. Genta RM, Ottesen EA, Poindexter R, Gam AA, Neva
FA, Tanowitz HB, Wittner M. Specific allergic sensitization to Strongyloides antigen in human strongyloidiasis. Laboratory Investigation 48:633-638, 1983.

22. Genta RM, Weil GJ. Antibodies to Strongyloides stercoralis larval surface antigens in chronic strongyloidiasis. Laboratory Investigation 47:87-90, 1982.

23. Gill GV, Bell DR, Fifield R. Lack of immunoglobulin $E$ response to longstanding strongyloidiasis. Clinical and Experimental Immunology 37:292-294, 1979.

24. Grove DI, Blair AJ. Diagnosis of human strongyloidiasis by immunofluorescence using Strongyloides ratti and $S$. stercoralis larvae. American Journal of Tropical Medicine and Hygiene 30: 344-349, 1981.

25. Higenbottam TW, Heard BE. Opportunistic pulmonary strongyloidiasis complicating asthma treated with steroids. Thorax 31:226-233, 1976.

26. Hoffman SL, Barret-Connor E, Norcross W, Nguyen D. Intestinal parasites in Indochinese immigrants. American Journal of Tropical Medicine and Hygiene 30: 340-343, 1981.

27. Kan SP, Singhr M, Cheah JS, Siak CL. Survey of helminthic infection in Singapore. Southeast Asian Journal of Tropical Medicine and Public Health 2: 190-195, 1971.

28. Kuberski TT, Gabor EP, Boudreaux D. Disseminated strongyloidiasis. A complication of the immunosuppressed host. Western Journal of Medicine 122: 504 509, 1975.

29. Lapierre J. Hien FV. L'anguillulose - Aspects cliniques, diagnostiques et therapeutiques - A propos de 300 cas observés. La Presse Medicale 28:1983-1986, 1970.

30. Leão RC, Barros MMT, Mendes E. Immunological study of human strongyloidiasis. I. Analysis of $\mathrm{IgE}$ levels. Allergollogia et Immunopatologia 8:31-34, 1980.

31. Neva FA, Gam AA, Burke J. Comparison of larval antigens in an enzyme-linked immunosorbent assay for strongyloidiasis in human. Journal of Infectious Diseases 144:427-432, 1981.

32. Sato $Y$, Takara $M$, Otsuru $M$. Detection of antibodies in strongyloidiasis by enzyme-linked immunosorbent assay (ELISA). Transactions of the Royal Society of Tropical Medicine and Hygiene 79:51-55, 1985.

33. Solomon $P$, Tintareanu G, Dancesco P. Recherches sur L'immunodiagnostic de la strongyloidose. Archives Roumaines de Pathologie Expérimentale et de Microbiologie 28:45-48, 1969 .

34. Tribouley-Duret J, Tribouley J, Appriou M, Megraud RN. Application du test ELISA au diagnostic de la strongyloidose. Annales de Parasitologia Humaine et Comparee 53:641-648, 1978. 